\title{
Establishment of traceability practices through halal assurance system (HAS) implementation
}

\begin{abstract}
For several years, Department of Islamic Development Malaysia (JAKIM) has started to introduce the Halal Assurance System (HAS) to enable companies to fulfil the needs of endcustomer. Besides, it allows companies to be more competent in ensuring halal assurance along the supply chain. The introduction of HAS as one of control system in order to sustain Halal integrity of a product is a remarkable effort. Even though HAS is currently compulsory for multinational company, but it is imperative for every player in halal industry to understand the importance of implementing the system properly. This is to ensure that the expected results can be maximized especially in providing traceability. There is a possibility of using multiple approaches of management or system due to the different guidelines, standards and practices that enables traceability in production. Thus, this paper discusses the similarity components of HAS, ISO22005:2007, and HACCP (Hazard Critical Control Point). This paper suggests that through the effective HAS implementation, firms can add value by having the traceability system in place.
\end{abstract}

Keyword: Halal assurance system; Halal food supply chain; Traceability 